\title{
How attitudes and beliefs about physics change from high school to faculty
}

\author{
Simon P. Bates, ${ }^{*}$ Ross K. Galloway, Claire Loptson, and Katherine A. Slaughter \\ Physics Education Research Group, School of Physics and Astronomy, University of Edinburgh, Edinburgh EH9 3JZ, United Kingdom
}

(Received 18 August 2010; published 8 November 2011)

\begin{abstract}
We present results of a pseudolongitudinal study of attitudes and beliefs about physics from different cohort groups ranging from final-year high school students in the UK to physics faculty $(N=637)$, using the Colorado Learning Attitudes about Science Survey (CLASS) instrument. In terms of overall degree of expertlike thinking, we find little change in cohorts at different stages of their undergraduate degrees, with a flat profile of expertlike thinking across the years of an undergraduate degree. Significant differences in overall CLASS scores occur for cohorts across entry and exit points of the undergraduate program. At the entry boundary, our data for high school students provides strong evidence of a selection effect, with students who intend to major in physics at university displaying more expertlike views than those students who are merely studying the subject to final year in high school. A similar effect is suggested at the exit boundary but is not definitive.
\end{abstract}

DOI: 10.1103/PhysRevSTPER.7.020114

PACS numbers: 01.40.Fk, 01.40.G-

\section{INTRODUCTION}

There is now a solid body of research indicating that students' attitudes towards and views about their subject, together with their conception of the nature of knowledge within the discipline, combine to form an epistemological standpoint that can influence their motivation and approaches they adopt towards study [1-5]. Student viewpoints and beliefs can be significantly different from those of expert practitioners, across dimensions such as how knowledge is structured (isolated fragments versus integrated ideas), where it comes from (dispensed by authority figures versus personal or collective endeavor), and how it is developed (knowledge as "certain" versus developing, refining, and improving understanding) [6]. In recent years, a number of assessment instruments have been developed to probe and assess the views, attitudes and beliefs of physics students. These include the Views of Nature of Science (VNOS) questionnaire [7], the Views About Science Survey (VASS) [8], the Maryland Physics Expectations Survey (MPEX) [9], and the Colorado Learning Attitudes about Science Survey (CLASS) $[10,11]$. Studies undertaken with these instruments have illustrated not only that the views of entrant undergraduates may be markedly different from those of experts in the discipline, but also that these differences often become reinforced after a period of instruction.

This study uses the CLASS instrument to undertake a pseudolongitudinal (cross-sectional) study of the relative expertise of different cohort groups, from final-year high

\footnotetext{
*S.P.Bates@ed.ac.uk
}

Published by the American Physical Society under the terms of the Creative Commons Attribution 3.0 License. Further distribution of this work must maintain attribution to the author(s) and the published article's title, journal citation, and DOI. school students to physics faculty in the UK. CLASS has been widely deployed with a variety of student cohorts, both by the instrument's designers and others, including collection of data from students outside North America in Saudi Arabia [12]. It has also been used to assess the expertlike thinking of students on degree programs other than physics, including engineering [11,13] and computer science [14], as well as in chemistry, for which a specific flavor of the survey instrument exists [15]. We adopt a similar approach to terminology as that utilized by Gire et al. [13]: the term "views" is used throughout to encompass the various aspects of expectations, attitudes, and beliefs.

Our aim in this work was to investigate how expertlike thinking and views develop in physics students over a period of time, starting before they commence undergraduate study and continuing beyond graduation. There have been several reports published of how the degree of expertlike thinking often decreases after an initial period of instruction, typically but not always a single semester [11], unless the curriculum is designed explicitly to confront (and, where necessary, resolve) students' epistemological thinking [16]. Far less has been reported about how expert views develop over a longer period of time. The recent study by Gire et al. [13] has suggested that it is possible that student views change little over a degree, and only those with the more expertlike views pursue study to final-year and postgraduate level. While four years of study in the subject undoubtedly improves technical ability and subject knowledge, could it be the case that this is not accompanied by a concomitant increase in expertlike thinking about the discipline?

Undertaking a longitudinal investigation by following a given cohort of students as they progress into, through, and beyond undergraduate study is a time-consuming process, necessitating data collection over an extended period of 
several years. Such a study has been reported by Barrantes et al. [17], surveying a cohort of 56 students doing a variety of different degrees at the commencement and end of their studies. We have recently reported a longitudinal study of the development of attitudes and beliefs of undergraduate physics students, tracking a cohort of students over the first three years of undergraduate study [18]. In this work, we take an alternative approach, in which we take "snapshot" data from a wide range of different cohorts, building up a pseudolongitudinal, or cross-sectional, data set that spans high school students to senior faculty. To validate this approach, we compare relevant portions of it with true longitudinal data collected by following a particular cohort for three consecutive academic sessions. The paper is organized as follows: in the next section, we present details of the methodology of the study. The results section presents the case for the validity of the pseudolongitudinal methodology, followed by our findings with particular emphasis on the transition points at the start and end of undergraduate study. We close with a discussion of the implications of these results and suggested future work.

\section{METHODOLOGY OF THE STUDY}

Before describing our findings, it is helpful to provide a little background context to the educational environment in which the study was undertaken. In the Scottish education system, it is not compulsory to take physics to final-year high school level (but around 15\% of all students do [19]). It is, however, compulsory to have a final-year school physics qualification in order to take an introductory level course in physics at university. In that sense, there is a subtle distinction between students we refer to in this paper as "nonmajors" and the usual interpretation. Our nonmajors are students who have taken high school physics but do not intend to undertake a degree in physics. They may have either elected to take a physics course as a first year option or it may be prescribed for a cognate degree discipline (e.g., geophysics).

A first degree in the Scottish system is usually four years duration, with the first year comprising a considerable amount of free choice in the curriculum (typically onethird). Students may enter the program with either one or two years of physics study beyond age 16 qualifications [20], which results in a heterogeneous cohort in terms of prior study and preparedness. A physics student would normally take a physics and a math course each semester, with one equivalent elective course choice. The enrollment in our introductory (first year) courses is typically between 200 and 300 , with approximately half of these intending to major in physics.

The physics curriculum at Edinburgh contains a mixture of both traditional and reformed courses that incorporate research-based instructional strategies. Many courses in the first two years make extensive use of studio-based teaching (in conjunction with lectures, rather than as a replacement), and use of clickers in lectures is widespread. The upper levels of the honors program is characterized by a wide range of more specialist courses, reflecting the broad range of research interests of a large academic department.

As well as the four years Bachelor of Science (B.Sc.) route, it is possible for a student to undertake an additional fifth year of study, resulting in an Integrated Masters degree in the discipline. Entry to this program is granted if students pass end of year exams in year 3 at a higher level (55\% or above). Approximately half of our students are eligible for and choose this option, but the actual proportions can vary substantially between years. The fifth year is primarily devoted to an individual research project with a group in the department, and this is reflected in the destinations of these students after graduation: around $80 \%$ of them continue on to postgraduate research work towards a Ph.D., either at Edinburgh or elsewhere.

The cross-sectional data presented in this paper were all collected during the academic year 2009-2010, between October and February (as part of an ongoing longitudinal study as detailed in Sec. III A, but that is not presented in detail here). We collected data from different educational levels: high school, undergraduate, postgraduate, and university staff. The survey data from high school was collected from two distinct groups of students. The first were students undertaking final-year high school physics courses, and the survey responses were collected in paper format by one of the authors visiting local schools (K. A. S.). The second cohort comprised students who were visiting the department as prospective undergraduate entrants. (Multiple completions of the survey, arising from coincidental overlap between these two cohorts, were discounted). Throughout the paper, we refer to these populations as "school" and "intending." Survey participation was entirely voluntary for school students, and took place during class times with support from teachers. Likewise, in all cases for survey responses from our undergraduate students, participation was voluntary and counted for no course credit. The data presented for the first year students pertain only to physics majors, who comprise approximately half of the cohort [21]. For years 1-3, the survey was completed in time-tabled class sessions (labs or workshops) and on paper. Responses from 4th and 5th year undergraduate students were collected online, utilizing the SurveyMonkey online tool [22], as part of a finalyear undergraduate project undertaken by one of the authors (C.L.). Postgraduate students who completed the survey were all in the first week of their first year of study of a Ph.D. and were collected via the same online survey. The final category of responders was university staff and comprised those respondents who were postdocs and research assistants or fellows $(N=15)$ and lecturers, readers, and professors $(N=59)$. No statistically significant differences in responses were found for these two separate 
staff groups, so they have been combined into a single cohort. These data were also collected via online survey, with email reminders to promote a good completion rate. Table I presents an overview of the total sample of $N=638$ and undergraduate completion rates from total class sizes. Survey data were subjected to the usual checks and balances to ensure reliability and integrity of responses [11]. We note in passing that a relatively small percentage of our responses failed the item on CLASS designed to weed out respondents not reading the survey questions [23]: around $4 \%$ in first year and on average less than $1 \%$ in later years.

The CLASS instrument measures the extent to which student responses align with the expert view ("favorable") or disagree with it ("unfavorable"), for each item on the survey instrument. Strength of agreement or disagreement is not considered, thus collapsing responses onto a three point scale of agree-neutral-disagree. Most items are represented in one or more of eight categories (e.g., personal interest, problem solving sophistication, etc.), and frequently what is reported is the overall extent to which a cohort group of responses agrees or disagrees with the expertlike view, aggregated over all scored items on the instrument, or just those items in particular categories. Throughout the paper, we refer to these values as "percentage of (un)favorable responses" for a given cohort, applied to a particular single item on the instrument, group of items in a particular category, or all items in the survey.

Responses were grouped by cohort and an analysis of variance (ANOVA) was used to probe for differences in the means and variances between years. Following this, an independent $t$-test was carried out between each of the year cohorts in order to establish any differences between years and groups. As no predictions about the direction of the differences between cohorts had been made prior to

TABLE I. Summary of survey responses by cohort and response rate for undergraduate years.

\begin{tabular}{lccc}
\hline \hline Level & Cohort & $\begin{array}{c}\text { Number of } \\
\text { responses }\end{array}$ & $\begin{array}{c}\text { Response } \\
\text { rate }(\%)\end{array}$ \\
\hline High school & $\begin{array}{c}\text { Doing physics } \\
\text { (School) }\end{array}$ & 92 & $\ldots$ \\
& $\begin{array}{l}\text { Intending physics } \\
\text { degree (Intending) }\end{array}$ & 65 & $\ldots$ \\
Undergraduate & Year 1 & 127 & 71 \\
& Year 2 & 105 & 71 \\
& Year 3 & 61 & 55 \\
Postgraduate & Year 4 & 57 & 77 \\
Staff & Year 5 & 23 & 66 \\
& Year 1 & 33 & $\ldots$ \\
& Postdocs or & 74 & $\ldots$ \\
\hline \hline & academic staff & & \\
\hline
\end{tabular}

data collection, a two-tailed $t$-test for samples with unequal variance was used. Further analysis on the spread of scores between certain year cohorts was undertaken using a $\chi$-squared analysis. The percentage of favorable responses were grouped into $10 \%$ bins and the resulting profiles compared between pairs of years [24]. Throughout the paper, inclusion of errors on reported data in figures and tables indicate the standard error on the mean and discussions of statistical significance correspond to $p$ values $<0.05$.

\section{RESULTS}

\section{A. Validation of pseudolongitudinal methodology}

We deployed the CLASS instrument to a wide variety of different cohort groups, resulting in a snapshot of their views from which we can assemble a pseudolongitudinal, or cross-sectional, picture of the way expertlike views develop across various education levels. A similar methodology has been reported by Gire et al. [13], looking at the differences in expertlike thinking between engineering and physics majors, and the changes in the latter over time. A cross-sectional or pseudolongitudinal sampling strategy is clearly a more expedient way of assembling this overview than tracking a given cohort of students as they progress through the various educational levels. For this to be valid, however, we need to be confident that the particular cohort group we are surveying at a single point in time, for example, second year undergraduate students studying physics, is representative of the whole population of second year undergraduates over a period of time.

One way we can collect evidence of validity is to compare our pseudolongitudinal data from a given cohort with data we have collected at the same level over time. The pseudolongitudinal results presented here were collected during the 2009-2010 academic session, but we have also been collecting CLASS data on all entrant undergraduates from the 2008-2009 session onwards. More detailed discussions of the results of this repeated pre and post surveying of first year students are presented elsewhere [18,25], including an analysis of the effect of a year's instruction and of degree intention and gender on CLASS scores. Here we present relevant data to validate the current methodology.

Table II shows the overall percentage of favorable and unfavorable responses for three successive first year cohorts in 2008-2009, 2009-2010, and 2010-2011 academic sessions, presenting matched data for physics majors. A common analysis is to look across rows of data to investigate the effect that a year of first year teaching has on CLASS scores. Here, we are more interested in looking down the columns of data to see how representative a given year's cohort is of the first year level over time. We see no statistically significant differences between any of the overall percentages of favorable or unfavorable responses 
TABLE II. Overall percentages of favorable and unfavorable CLASS responses, compared to expert views, for three consecutive first year cohorts $(N=111,93,54)$, collected pre and post first year teaching. Values in brackets denote the standard error.

\begin{tabular}{lcccc}
\hline \hline & \multicolumn{2}{c}{ Pre first year teaching } & \multicolumn{2}{c}{ Post first year teaching } \\
Year cohort & Favorable & Unfavorable & Favorable & Unfavorable \\
\hline $2008-2009$ & $72(1)$ & $11(1)$ & $71(1)$ & $13(1)$ \\
$2009-2010$ & $73(1)$ & $11(1)$ & $68(2)$ & $15(1)$ \\
$2010-2011$ & $73(2)$ & $13(1)$ & $72(2)$ & $13(1)$ \\
\hline \hline
\end{tabular}

for the three cohorts, for either pre- or post-teaching data sets.

This comparison gives us confidence in adopting a pseudolongitudinal methodology. While the data in the columns of Table II are not identical from one year to the next, there are no statistically significant differences in the time frame over which we have been collecting data. However, we need to be cautious about overextending the time frame for which we can confidently make the assertion that "a year one undergraduate cohort is much the same as any other," but this appears to be valid for (at least) three years. We likewise assume that the same holds for cohorts at other levels we have surveyed (i.e., high school students, other undergraduates, postgraduate, staff, etc.). Additional CLASS response data we have recently collected from a large number $(\approx 500)$ of UK members of the Institute of Physics, of whom nearly 200 are in the category we refer to as staff, support this assumption [26].

Cross-sectional data collected from different cohort groups in a single year are by definition not matched data and it is important to check that using nonmatched data is valid. The easiest way to do this is by comparison of cross-sectional data with fully longitudinal data for a single cohort. Elsewhere we have presented results of a fully longitudinal study using CLASS, with fully matched data from a cohort group $(N=35)$ over three successive years of study [18]. We find that there are no statistically significant differences in data collected via a fully or pseudolongitudinal methodology. This is true for both favorable and unfavorable percentages from undergraduate cohorts in years 1,2, and 3 of study.

\section{B. Trends in expertlike thinking across educational levels}

Figure 1 presents a summary of the overall CLASS scores (both favorable and unfavorable responses) for the range of cohorts we have surveyed in this study. The nine cohort groups can be thought of as belonging to one or more of three, overlapping populations: those straddling the entry point to university study (cohorts $1-3$ ), undergraduate students (cohorts 3-7), and those straddling the exit point towards becoming a professional physicist (cohorts 6-9).

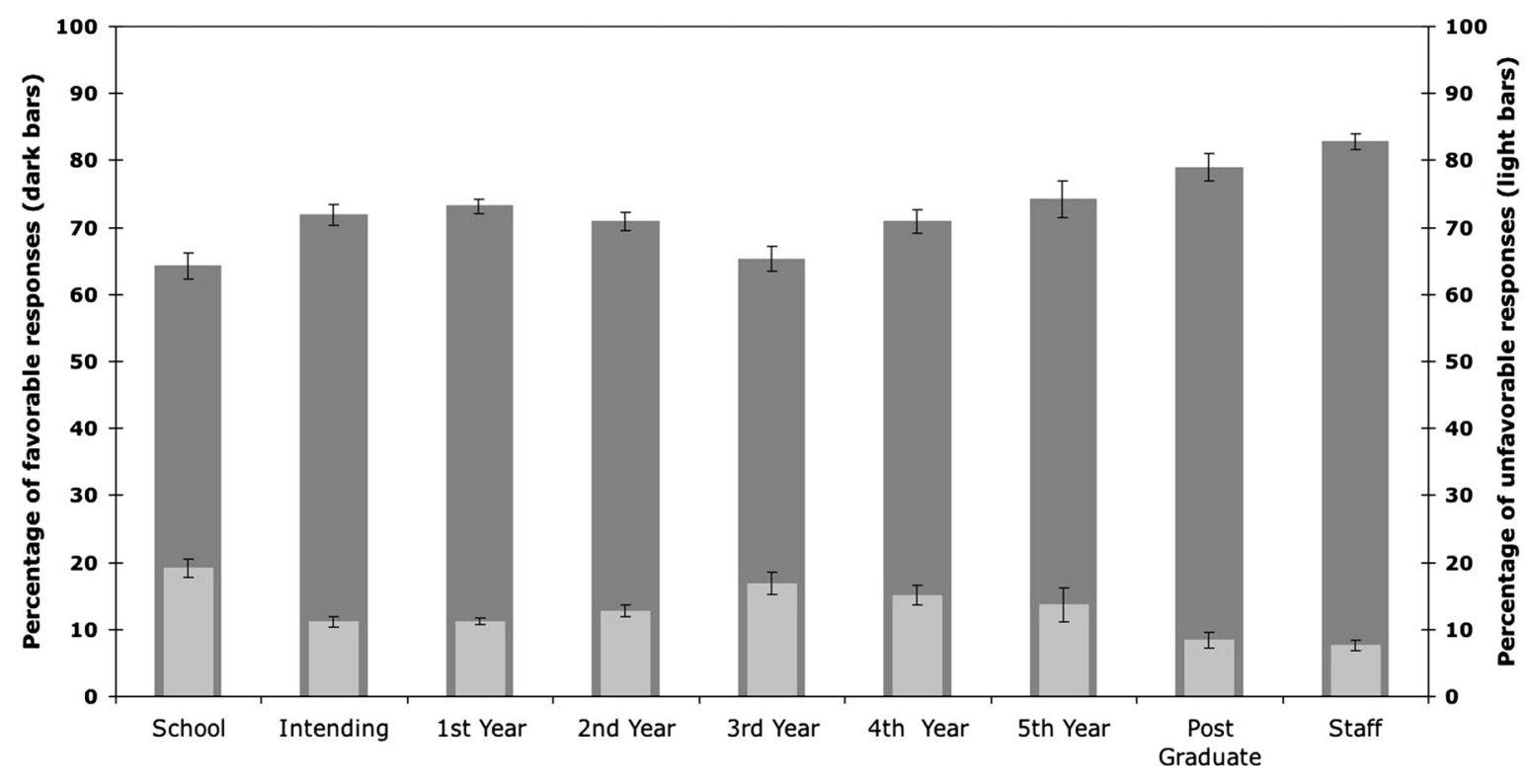

FIG. 1. Overall percentages of favorable and unfavorable responses from survey cohorts. Favorable and unfavorable responses are shown as dark and light bars, respectively. 
There are several features we highlight from data presented in the figure. The first is that both the percentage of overall favorable and unfavorable responses is remarkably consistent across the five years of undergraduate study, with the exception of year 3 results, which we discuss in more detail below (Sec. III C). An ANOVA analysis reveals no significant differences in either favorable or unfavorable scores between any pair of undergraduate cohorts, with the exception of some involving year 3. Excluding this year 3 cohort, the range (maximum-minimum) of favorable and unfavorable scores for undergraduate cohorts is less than $5 \%$.

In contrast to this rather flat scenario across undergraduate study, statistically significant changes between the scores of cohorts are found at the entry and exit points to the undergraduate program, i.e., in the cohort triads of high school-intending physics-year 1 and year 4-year 5postgraduate. These transitions, on entry and exit, are discussed in more detail in Secs. III D and III E. The broad overview of the data presented in Fig. 1 suggests an undergraduate plateau of expertlike thinking as measured by CLASS, with significant differences at entry and exit points.

\section{Decrease in expertlike views in year 3}

Year 3 stands out in Fig. 1 as the only cohort group exhibiting a noticeably different trend in favorable and unfavorable CLASS scores: the former are lower than others in the undergraduate cohorts, the latter greater. Between the year 2 and year 3 cohorts (and between year 3 and year 4) we see a statistically significant decrease for responses that agree with expertlike thinking. Differences in the percentages of unfavorable response are significant between year 2 and 3 cohorts but not for the year 3 and 4 cohorts. We believe that these data points are anomalous, rather than being indicative of something inherently different in this year of study and/or within this particular student cohort. Data we have subsequently collected from the third year undergraduate cohort in 20102011 (i.e., the second year undergraduate cohort in this study) result in overall percentage of favorable and unfavorable CLASS responses of 68(3)\% and 15(1)\%, respectively. These values are not statistically significantly different from those for the year 2 or 4 cohorts presented here. This one seemingly anomalous data point does not alter the basic picture that we observe in the trend in levels of expertlike thinking in the undergraduate cohort, which is predominantly flat across all years of the program. The changes in expertlike thinking we find at transition points into and out of the undergraduate program are much larger than this anomalous year 3 inconsistency and are discussed in the following two subsections.

\section{Differences in expertlike views across the entry transition}

In this section, we examine the changes in CLASS scores for the three cohorts that span the entry to undergraduate study: those students taking a final-year physics course at high school (school), students at the same educational level but who have declared an intention to undertake a physics degree at university (intending), and our first year physics majors cohort. We recall that these are three distinct cohorts with no overlap in the students surveyed between the school and intending cohorts (but in principle the intending cohort forms a subset of the wider school population) and that all data were collected within a

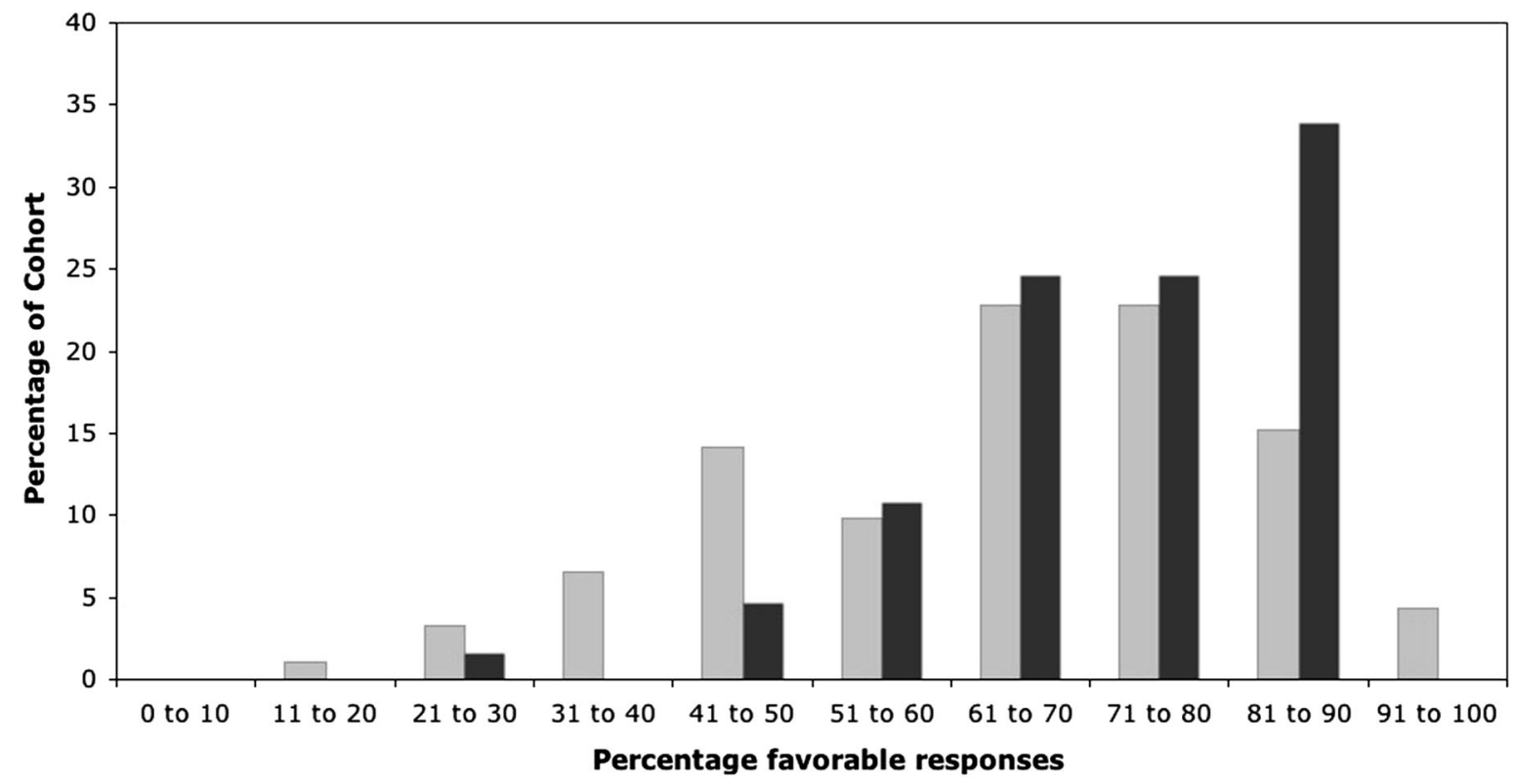

FIG. 2. Frequency of CLASS favorable scores for school (light gray bars, $N=92$ ) and intending (dark gray bars, $N=65$ ) cohorts. 
time period of a few weeks during the same academic year. We find statistically significant differences in the overall percentage of favorable responses between school and intending cohorts $(p=0.002)$, and between school and year $1(p<0.0001)$, but not between intending and year 1. (Similar patterns of significance are seen when considering the unfavorable CLASS scores.)

Students intending to study physics at university appear to hold significantly more expertlike views than those simply studying the subject to final year high school. The expertise of intending students' views appears to be indistinguishable from that of first year undergraduates. We suggest that since intending students are a subset of the total population of students taking final-year high school physics, it should be possible to identify similarly expertlike views among the range of responses from students in the final year of high school. In terms of our data, we can look at the range of CLASS scores, rather than simply cohort averages and standard errors, for the school and intending cohorts; this is illustrated in Fig. 2. It illustrates that despite a significantly different profile of responses between the two cohorts $\left(\chi^{2}=11\right.$, d.o.f. $\left.=4, p<0.026\right)$, there is a high degree of overlap between the two distributions at high percentages of favorable responses. This is thus evidence that the highly expert intending cohort is present within the larger, but on average less expert, school cohort (as must be the case since both were surveyed at similar times, leaving no opportunity for substantial changes to occur to the intending subcohort before taking the survey). A significant fraction (but by no means all) of these students at the higher end of the school distribution may elect to do a physics degree, at Edinburgh or anywhere else. It is not clear which one of choosing to undertake a physics degree or holding more expertlike views is caused by or causes the other, and this represents an interesting area for future study. We note in passing from Fig. 2 that approximately one-third of the intending cohort sample score a favorable response percentage in the same decile as the staff cohort in Fig. 1.

\section{E. Changes in expertlike views across the exit transition}

In addition to the significant differences in expertlike views of cohorts across the entry transition to undergraduate study, similar differences in expertlike views are also seen across the exit transition. We recall that there are two exit points to the Scottish first degree: either at B.Sc. level, normally after 4 years of study, or at Integrated Masters level (M.Phys.), normally after five years of study. More of the former (B.Sc. graduates) pursue careers outside physics; the vast majority of the latter (M.Phys. graduates) carry on to postgraduate research study. This structure effectively extends the on-exit transition across three of our cohorts: years 4 and 5 at undergraduate level and postgraduate. Figure 1 shows a clear trend across these three cohorts of increasing (decreasing) percentage of favorable (unfavorable) responses. The only statistically significant differences between overall favorable responses for pairs of cohorts in this triad is found between year 4 and postgraduate $(p=0.003)$. Differences between year 4 and year 5 , and year 5 and postgraduate, were found to not be significant, despite a rising trend in overall percentages of favorable responses. Equivalent tests between pairs of percentages of unfavorable responses followed a similar pattern: no statistically significant differences between year 4 and 5 or year 5 and postgraduate, but year 4 to postgraduate differences were statistically significant.

Year 5 represents a stepping stone year, intermediate between undergraduate B.Sc. and postgraduate research study, both in curriculum and in terms of the percentages of expertlike views of the respective cohorts. It is intriguing to speculate if a similar selection effect to that observed at the entry transition is in effect here: are those students with more expertlike views preferentially selecting to continue towards a Ph.D. in physics? There is certainly evidence for this from overlapping distributions of the overall favorable scores of the three cohorts (albeit with smaller cohort sizes than presented in Fig. 2). In addition, we have also surveyed 2010 graduates from our programs (at both B.Sc., year 4 and M.Phys., year 5) asking them about future career plans. The responses are suggestive of a relationship between overall CLASS favorable score and intention to undertake a Ph.D., but not strongly enough to claim any statistical significance. This is in part due to the relatively small number of students responding to a postgraduation survey about their intended immediate future $(N=25)$ but also due to a non-negligible fraction of students being genuinely undecided at this point.

\section{DISCUSSION}

Our results indicate that students' views, as measured by the CLASS instrument and compared to those of experts, are relatively unchanged over the course of their undergraduate study. It seems that, contrary to reasonable expectations, undertaking and completing a degree in physics does not lead to a corresponding cohort average increase in expertlike thinking. We can speculate as to the reasons for this relatively flat landscape. On the one hand, our students intending to do a physics degree arrive at our doors possessing relatively high levels of expertlike thinking (certainly somewhat higher than other data that have been reported elsewhere [11,12]). Approximately one-third of our high school cohort intending to study physics scores a favorable response percentage approximately equal to that of academic staff. One could make the argument that our students start relatively expert, and stay that way. On the other hand, one can view this from a different standpoint and be critical of the fact that, with such good raw materials coming through our doors, we do little to build on this during the four or five years these students are part of our 
undergraduate community. It is likely that the reality is some combination of both.

We see levels of expertlike thinking increase beyond undergraduate study, consistent with the views of many of our postgraduates who state that this is when they begin to "feel like a real physicist." This is the time when students begin to really undertake on a full-time basis the authentic practices of the discipline: pure or applied research in a topic of their choosing and perhaps contributing to the teaching of the next generation of undergraduates as teaching assistants. However, our data suggest (but cannot confirm) that this is due to a selection effect at the end of undergraduate study: those students with the more expertlike views as final-year undergraduates tend to be the ones who carry on to postgraduate study.

Perhaps the most surprising finding of this study is the clarity with which a similar selection effect appears to be at work at the entry point to the undergraduate physics program. There is a very significant difference in degree of expertlike thinking between those students who are doing a final-year high school course in physics (and are thus, subject to obtaining the requisite entry grades, in principle qualified to take the subject at university) and those who have already made the choice to do a physics degree. We have found similar effects when looking at the degree intentions of all entrant students taking our Physics 1 course [25]: physics majors arrive with more expertlike views than those in other science degree programs. This has also been observed by Gire et al. and others [11,13] for differences between physics and engineering majors. This begs the obvious question of what it is that shapes the development of student views prior to arriving at university, or even prior to choosing to study physics at university. May a similar effect be operating at a younger age when course choices are made? We are not aware of other published data of CLASS surveys of high school students, so we cannot judge if this is a peculiarity of Scottish students or their curriculum. We intend to undertake a more detailed study in the future.

The development of attitudes of undergraduate physics students may be reconciled with Perry's extensive work on the intellectual and ethical development of attitudes $[27,28]$. Other studies have found that students frequently become less expert in their views after a period of undergraduate teaching, and this work has illustrated that expertise appears relatively unchanging over the course of an undergraduate degree. In Perry's scheme, nine positions of development are aggregated into four sequential categories that characterize development: dualism, multiplicity, contextual relativism, and commitment within relativism. Few undergraduate students reach the uppermost category, which deals more with development of identity rather than a shift in understanding about the nature of knowledge [29]. The lowest category is characterized by a view of the subject often seen among some entrant undergraduates. A student operating within the Perry category of dualism believes knowledge is either right or wrong, and dispensed from an authority. Their job as a student is to accept this knowledge and learn as much as possible. Multiplicity represents an extension to dualism, with the addition of "not yet known" as an alternative to right and wrong. The student operating at this stage not only finds knowledge but also assesses and evaluates it. The biggest shift between Perry categories is seen moving from multiplicity to contextual relativism. Here, a model of thinking of knowledge as "right and wrong but with lots of exceptions" is supplanted by the view that knowledge is relative and bound by context, with few absolute right and wrong answers.

Evidence of different positions on the Perry scale are clearly demonstrated in different responses to CLASS survey statements, for example, CLASS item 10 ("There is usually only one correct approach to solving a physics problem"). Agreement with this item, the more novice view, represents a dualist perspective, whereas disagreement with it represents a higher Perry category, of multiplicity and/or relativism. In Perry's model, retreat to previous categories, often accompanied by a drop in confidence, is one method of dealing with the uncertainty that comes from making the transition to a relativist viewpoint. The development of more expertlike thinking may be seen as occurring in conjunction with transition to higher categories. It would be interesting to investigate this association further, by correlating particular CLASS responses of students with their location within Perry's categories or those of modified Perry schemes.

\section{CONCLUSION}

We have administered the CLASS survey of attitudes and beliefs about physics to a wide range of student cohorts, ranging from final-year high school students, through all years of the undergraduate program at Edinburgh, to postgraduates and staff. We find that expertlike thinking, as measured by the CLASS instrument, is largely unchanged over the duration of the undergraduate program. Significant changes in the degree of expertlike thinking occur at both the entry and exit points of the undergraduate program, which appear to be a selection effect with those with more expertlike views choosing to do physics at university or pursue a postgraduate research degree. Comparison with other similar recently published data, and informal communications with colleagues elsewhere, suggest that this is probably not specific to our students or their prior educational experiences.

\section{ACKNOWLEDGMENTS}

We are grateful to all the staff who gave up class time so that we could conduct this investigation, and to the students who participated in it. We acknowledge financial support to K. A. S. from the University of Edinburgh's Principal's Teaching Award Scheme. 
[1] C. Ogilvie, Changes in students' problem-solving strategies in a course that includes context-rich, multifaceted problems, Phys. Rev. ST Phys. Educ. Res. 5, 020102 (2009).

[2] M. B. Paulsen and K. T. Feldman, The conditional and interaction effects of epistemological beliefs on the self-regulated learning of college students: Cognitive and behavioral strategies, Res. High. Educ. 48, 353 (2007).

[3] C.S. Dweck, Self-Theories: Their Role in Personality, Motivation and Development (Psychology Press, Philadelphia, PA, 1999).

[4] J. S. Eccles and A. Wigfield, Motivational beliefs, values and goals, Annu. Rev. Psychol. 53, 109 (2002).

[5] L. Lising and A. Elby, The impact of epistemology on learning: A case study from introductory physics, Am. J. Phys. 73, 372 (2005).

[6] M. Schommer-Aitkins, Personal Epistemology: The Psychology of Beliefs about Knowledge and Knowing (L. Erlbaum Assoc., Mahwah, NJ, 2002), pp. 103-118.

[7] N. G. Lederman, F. Abd-El-Khalick, R. L. Bell, and R. S. Schwartz, Views of nature of science questionnaire: Toward valid and meaningful assessment of learners' conceptions of nature of science, J. Res. Sci. Teach. 39, 497 (2002).

[8] I. Halloun and D. Hestenes, Interpreting VASS dimensions and profiles for physics students, Sci. Educ. 7, 553 (1998).

[9] E.F. Redish, R. N. Steinberg, and J.M. Saul, Student expectations in introductory physics, Am. J. Phys. 66, 212 (1998).

[10] W. K. Adams, K. K. Perkins, M. Dubson, N. D. Finkelstein, and C.E. Wieman, The design and validation of the Colorado Learning Attitudes about Science Survey, AIP Conf. Proc. 790, 45 (2005).

[11] W. K. Adams, K. K. Perkins, N. S. Podolefsky, M. Dubson, N. D. Finkelstein, and C.E. Wieman, New instrument for measuring student beliefs about physics and learning physics: The Colorado Learning Attitudes about Science Survey, Phys. Rev. ST Phys. Educ. Res. 2, 10101 (2006).

[12] H. Alhadlaq, F. Alshaya, S. Alabdulkareem, K. K. Perkins, W. K. Adams, and C.E. Wieman, Measuring students' beliefs about physics in Saudi Arabia, AIP Conf. Proc. 1179, 69 (2009)

[13] E. Gire, B. Jones, and E. Price, Characterizing the epistemological development of physics majors, Phys. Rev. ST Phys. Educ. Res. 5, 010103 (2009).

[14] C. Lewis, M. H. Jackson, and W. M. Waite, Student and faculty attitudes and beliefs about computer science, Commun. ACM 53, 78 (2010).

[15] J. Barbera, W. K. Adams, C.E. Wieman, and K. K. Perkins, Modifying and validating the Colorado
Learning Attitudes about Science Survey for use in chemistry, J. Chem. Educ. 85, 1435 (2008).

[16] E. F. Redish and D. Hammer, Reinventing college physics for biologists: Explicating an epistemological curriculum, Am. J. Phys. 77, 629 (2009).

[17] A. Barrantes, A. Pawl, and D.E. Pritchard, What do seniors remember from freshman physics?, AIP Conf. Proc. 1179, 47 (2009).

[18] R. K. Galloway K. A. Slaughter, S. P. Bates, A longitudinal study of the development of attitudes and beliefs towards physics, in Proceedings of the Physics Education Research Conference, Omaha, NE, 2011 (to be published).

[19] Scottish Qualifications Agency, National courses 2009, 2009.

[20] Age 16 qualifications mark the end of compulsory secondary-level schooling in the UK, with the majority of students electing to continue to further study of up to two years duration.

[21] Nonmajors cannot take advanced level courses beyond year 2 and we exclude them here as we are interested in the development of attitudes and beliefs of physics students as they progress through their degree.

[22] SurveyMonkey: Free online survey and questionnaire tool, http://www.surveymonkey.com.

[23] The wording of the item is "We use this statement to discard the survey of people who are not reading the questions. Please select agree-option 4 (not strongly agree) for this question to preserve your answers."

[24] A. Field, Introducing Statistical Methods (Sage Publications Ltd., London, 2009), 3rd ed.

[25] K. A. Slaughter, S.P. Bates, and R. K. Galloway, The changes in attitudes and beliefs of first year physics undergraduates: A study using the CLASS survey, Int. J. Innovations Sci. Math. Educ. 19, 29 (2011).

[26] For this cohort of nearly 200 staff, the overall percentage of favorable and unfavorable CLASS responses are not statistically significantly different from those presented for the sample of 59 staff in this paper. A full presentation of results from this data set will be forthcoming.

[27] W. G. Perry, Forms of Ethical and Intellectual Development in the College Years: A Scheme (JosseyBass Inc., San Fransisco, 1999).

[28] B. K. Hofer and P. R. Pintrich, The development of epistemological theories: Beliefs about knowledge and knowing and their relation to learning, Rev. Educ. Res. 67, 88 (1997).

[29] W.S. Moore, Student and Faculty Epistemology in the College Classroom: The Perry Schema of Intellectual and Ethical Development (Greenwood, Westport, CT, 1994), pp. 46-67. 